\title{
Thermal analysis of impact damage of prepreg composite materials
}

\author{
by P. Bagavac*, L. Krstulović-Opara* and Ž. Domazet*
}

\begin{abstract}
* Faculty of Electrical Engineering, Mechanical Engineering and Naval Architecture, University of Split, Croatia,
\end{abstract} (petra.bagavac; opara; domazet)@fesb.hr

\begin{abstract}
Composite materials are employed in industry at a high rate, and the demand is increasing. Recently, prepreg carbon and aramid-carbon composite structures, when compared to carbon fiber reinforced polymer composites, have attracted increasing attention due to their better impact damage resistance. In order to characterize the material, impact test according to EN DIN 6038 was carried out including infrared acquisition of impact. Based on the cooled MW InSb detector IR camera, the spread of damage was observed during impact test.
\end{abstract}

\section{Introduction}

The usage of prepreg in automotive industry is used at relatively limited quantities in comparison with other techniques like automated tape lay-up and automated fiber laying. The main reason behind this is the relative high cost of prepreg fibers as well as the compounds used in molds. Although, prepreg is very popular material in production of supercars and presented research is beginning of our cooperation with local manufacturer of electric supercars. Apparently, car crash tests are expensive and a qualitative analysis of the stability of the material exposed to impact load is necessary at the initial material design stage. Composite materials are extremely isotropic and the choice of laminate setup and the order of stacking can lead to significant savings in production. This problem is cited among other authors [1-5].

\section{Experimental setup}

The EN DIN 6038 impactor is used to test material resistance and response when subjected to impact, Fig. 1. The device consists of a supporting construction tube, thorn and frame for clamping the sample. It is possible to place specimens of different thickness on the frame. A thorn is released from height thus producing a dynamic impact on the surface of specimen. An IR camera is placed underneath the specimen on, i.e. facing the tension side during impact loading. IR camera is capturing temperature distribution throughout the duration of the experiment.

It is possible to vary the height from which the thorn falls to the sample by free fall and the weight of the thorn. In this way, we select the impact energy $(E=m g h)$ and the amount of motion $(p=m v)$ by which the thorn strikes the surface of the sample. This is a very simple impactor and used to produce the damage on specimens that later on were subjected to NDT.

\section{Materials and experiment parameters}

To evaluate the impact behavior of composite structures, 3 different composite materials were tested: CFRP001, CFRP002 and CFRP003 with overall dimensions $150 \times 150 \mathrm{~mm}$, Fig. 2. Specimens were made from RAW006-010319 SHD DF314-C650-HS-3K-1250mm carbon prepregs and matured for 18 hours in autoclave at $75^{\circ} \mathrm{C}$ and 1.5 bar pressure. Lay-up plan is given at Table 1.

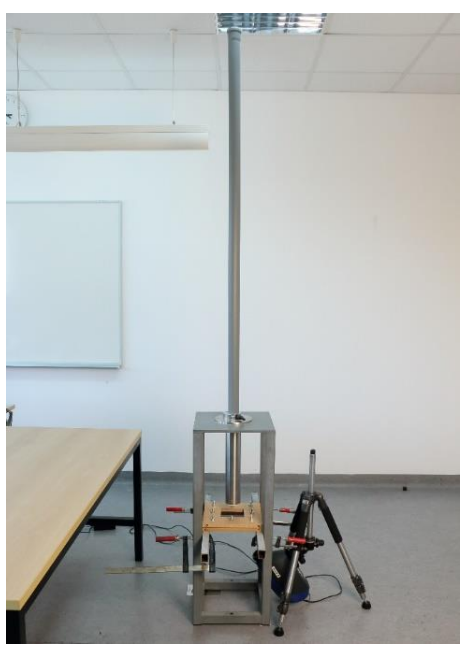

Fig. 1. Experimental setup EN DIN 6038 impactor

Samples were damaged by $R=8 \mathrm{~mm}$ EN DIN 6038 impactor. A thorn weighing $1000 \mathrm{~g}$ was used and the free fall height was varied. First set of specimens was damaged so that the thorn was released from a height of $2 \mathrm{~m}$, with an impact energy of $19.61 \mathrm{~J}$ and the maximum speed of $6.26 \mathrm{~m} / \mathrm{s}$ at which the thorn struck the surface of the specimen. The second set of specimens was damaged by releasing the thorn from a height of $1 \mathrm{~m}$, with an impact energy of $9.80 \mathrm{~J}$ and the maximum speed of $4.43 \mathrm{~m} / \mathrm{s}$ at which the thorn struck the surface of the specimen. Used camera is a MW InSb FLIR $5000 \mathrm{SC}$ with acquisition frequency $492 \mathrm{fps}$ and the resolution $160 \times 128$ pixels.

Table 1. Lay-up plan for used specimens

\begin{tabular}{|l|l|l|l|}
\hline SPECIMEN & LAY-UP PLAN & THICKNESS [mm] & SPECIFIC WEIGHT [g/mm3] \\
\hline CFRP0001 & 5-PLY carbon & 2.41 & \\
\hline CFRP0002 & 2-PLY carbon & 0.98 & \\
\hline CFRP0003 & 4-PLY carbon + 1-PLY aramid & 2.15 & \\
\hline
\end{tabular}




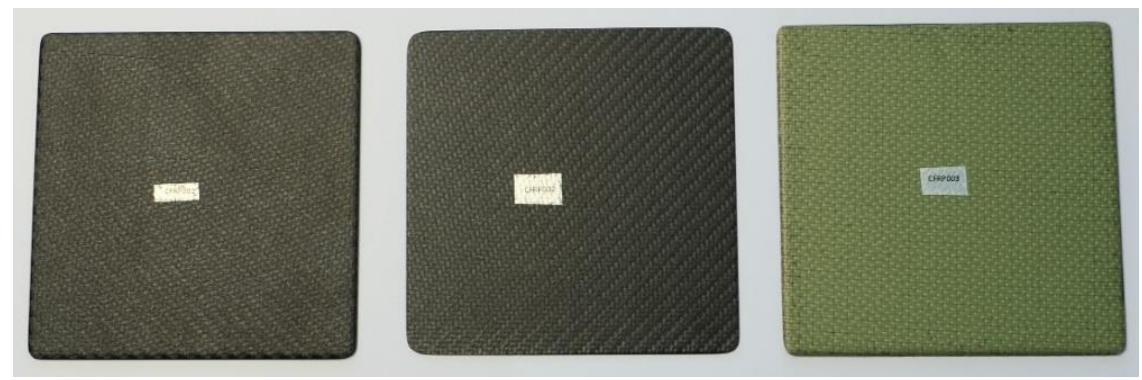

Fig. 2. Specimens: CFRP001, CFRP002 and CFRP003

\section{Results and conclusion}

A shown at Fig. 3., the CFRP003 specimen exhibits a more extensive damaged area, as the intralaminar damage in the CFRP003 specimen is more detectable than in the CFRP001 specimen for same geometry and impact parameters.
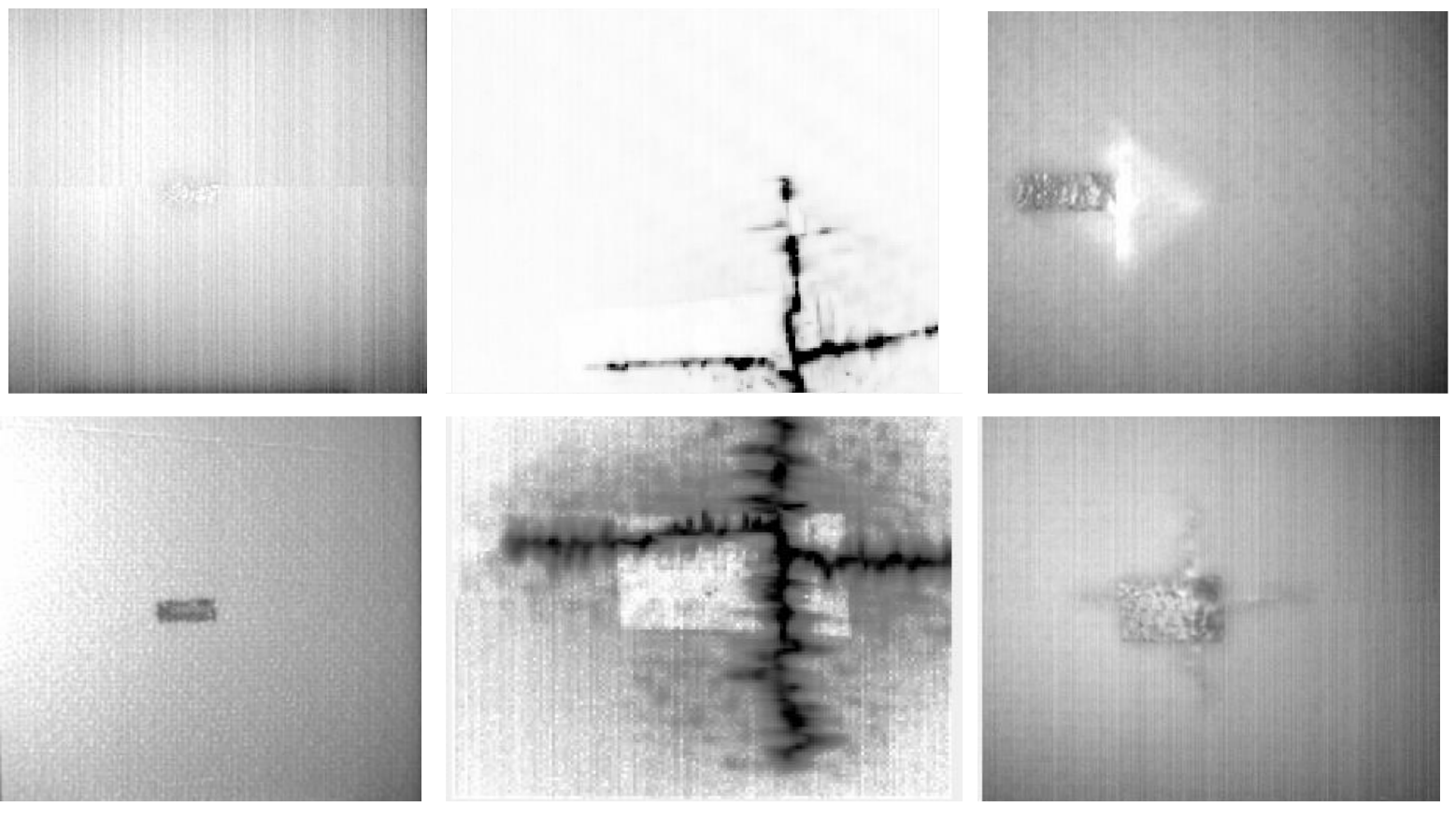

Fig. 3. Thermal images for specimen CFRP001 and CFRP003 impacted with total energy of $19.68 \mathrm{~J}$ : a) before impact, b) during impact and c) after impact

Infrared imaging used in this paper contributed to the understanding of impact damage expansion. This analysis can provide basis for roving design and evaluation when various fiber orientations and setups are considered. It is expected more research work in order to understand mechanical impact behavior of new composite materials.

\section{REFERENCES}

[1] Meola C., Carlomagno G. M. Impact damage in GFRP: New insights with infrared thermography. Composites: Part A 41: 1839-1847, 2010

[2] Boccardi S., Carlomagno G. M., Simeoli G., Russo P., Meola C.. Evaluation of impact-affected areas of glass fibre thermoplastic composites from thermographic images. Meas. Sci. Technol. 27075602 (12pp), 2016

[3] Meola C., Boccardi S., Carlomagno G. M., Boffa N. D., Ricci F., Simeoli G., Russo P. Impact damaging of composites through online monitoring and non-destructive evaluation with infrared thermography. NDT\&E International 85: 34-42, 2017

[4] Meola C., Carlomagno G. M.. Infrared thermography of impact-driven thermal effects. Appl Phys A 96: 759-762, 2009

[5] Krstulović-Opara L., Klarin B., Neves P., Domazet Ž. Thermal imaging and Thermoelastic Stress Analysis of impact damage of composite materials. Engineering Faliure Analysis 18: (2), 713-719, 2011 